\title{
COMO AS CIDADES BRASILEIRAS ESTÃO LIDANDO COM O AIRBNB? COLOCANDO A REGULAÇÃO EM PERSPECTIVA
}

HOW ARE BRAZILIAN CITIES DEALING WITH AIRBNB? PUTTING THE REGULATIONS INTO PERSPECTIVE

\author{
Gisela Cunha Viana Leonelli ${ }^{1}$ \\ Rafael Braga de Souza ${ }^{2}$
}

\section{RESUMO}

Nos últimos anos, empresas têm prosperado no ambiente digital a partir de premissas do compartilhamento de produtos e serviços. O Airbnb é uma empresa que opera dentro dessa lógica conhecida como Economia do Compartilhamento e tem gerado impactos no ambiente urbano. Nesse contexto, cidades, principalmente na Europa e nos EUA, têm estabelecido marcos regulatórios com estratégias variadas, visando ampliar os benefícios e mitigar os impactos negativos dessa plataforma. No entanto, é desconhecida a legislação voltada para o Airbnb no Brasil e sua abordagem. O objetivo desse trabalho é contrastar as legislações brasileiras concernentes ao Airbnb com os marcos regulatórios internacionais. O método aplicado foi comparativo entre os objetivos das legislações aplicadas nas cidades estrangeiras e as legislações brasileiras. Constatou-se que as leis brasileiras têm abordagens que não exercem efetivo controle e monitoramento sobre o Airbnb. Além disso, diferenciam-se das legislações internacionais em termos de problemática enfrentada, uma vez que estas buscam garantir habitação a preços acessíveis, enquanto as poucas leis brasileiras vigentes privilegiam a concorrência mais equilibrada com o mercado de hospedagem.

Palavras-chave: Airbnb; Regulação Urbana; Economia do Compartilhamento; dinâmica imobiliária; Mercado de hospedagem

\footnotetext{
${ }^{1}$ Arquiteta e Urbanista, professora da Faculdade de Engenharia Civil, Arquitetura e Urbanismo nos cursos de graduação em Engenharia Civil e Arquitetura e Urbanismo e no Programa de Pós-graduação em Arquitetura, Tecnologia e Cidade (PPGATC-FEC/UNICAMP). UNICAMP - Universidade Estadual de Campinas - Brasil. ORCID Id: https://orcid.org/0000-0002-2371-3092 Lattes: http://lattes.cnpq.br/0925768769790678 E-mail: gisela@fec.unicamp.br

${ }^{2}$ Arquiteto e Urbanista, mestre pelo Programa de Pós-graduação em Arquitetura, Tecnologia e Cidade. (PPGATC - FEC/UNICAMP). UNICAMP - Universidade Estadual de Campinas - Brasil. ORCID Id: https://orcid.org/00000003-0441-4051 Lattes: http://lattes.cnpq.br/2323629621082657 E-mail: rbragadesouza@gmail.com
} 


\section{ABSTRACT}

In the recent years, companies have flourished in the digital environment based on the premises of sharing products and services. Airbnb is a company that operates within this logic known as the Sharing Economy and has had impacts on the urban environment. In this sense, some cities, especially in Europe and the USA, have established regulatory frameworks with varied strategies aiming to expand the platform's benefits and mitigate its negative impacts. However, the Brazilian policies regarding Airbnb and its approach is unknown. This paper aims to contrast the Brazilian legislation regarding Airbnb with the international public policies. The applied method was comparative between the objectives of the legislation applied in foreign cities and the brazilian legislation. We found that the Brazilian laws do not effectively control and monitor Airbnb. In addition to being far from international legislation in terms of the problems faced, the international laws seek to guarantee affordable housing, while the Brazilian ones favor more balanced competition with the lodging industry.

Keywords: Airbnb; Land Policy; Sharing Economy; Real Estate Dynamics; Lodging Industry

\section{INTRODUÇÃO}

O Airbnb é uma ferramenta online que oferece uma nova maneira de hospedagem para usuários no mundo todo, conectando pessoas que tem imóveis (ou partes deles) disponíveis para aluguel em curtas temporadas com pessoas quem tem interesse em se hospedar, através da Internet. Antes dele, as formas de hospedagem se resumiam aos tradicionais hotéis, pousadas, albergues e aos aluguéis de temporada. Fundado em 2008, pelos estudantes universitários Brian Chesky, Joe Gebbia e Nathan Blecharczyk, a plataforma começou com o aluguel de três colchões de ar, como o nome de "Air Bed and Breakfast". Hoje está presente em mais de 191 países, 65 mil cidades com quase 3 milhões de propriedades disponíveis, desde castelos a casas na árvore, além de já ter mediado a hospedagem de mais de 180 milhões de pessoas no mundo inteiro (AIRBNB, 2016).A plataforma é parte de um novo modelo de negócios chamado "Economia do Compartilhamento". As iniciativas que fazem parte desse modelo preconizam pelo acessar um produto ou serviço, que se utiliza por tempo limitado ao invés de comprá-lo e mantê-lo ocioso pela maior parte do tempo (KOOPMAN; MITCHEL; THIERER, 2015). A Economia do Compartilhamento tem gerado controvérsias porque, apesar de possibilitarem serviços e trocas muitas vezes análogos a outros já existentes no mercado tradicional, operam na ausência da regulação (KATZ, 2015). 
Estando o Airbnb inserido nesse contexto, sua regulação também tem se dado de maneira controversa. Cidades no mundo todo têm criado suas regulações variando suas estratégias que buscam mitigar os impactos percebidos em cada uma delas. Nieuwland e Melik (2018) estabelecem uma categorização dessas regulações que, por mais diferentes que possam ser, assemelham-se em termos de objetivos e abordagens. O Brasil tem apenas duas cidades com legislação específica para regulamentação do Airbnb e um projeto de lei em nível federal.

O objetivo deste artigo é responder como as cidades brasileiras, até o presente momento, têm regulado o Airbnb em contraste com as regulamentações no panorama internacional. Metodologicamente, primeiro foi realizada a revisão bibliográfica nos seguintes temas: regulação da Economia do Compartilhamento, impactos do Airbnb e regulação do Airbnb no mundo e no Brasil. Foram utilizadas as bases Web of Science, Scopus e Scielo para identificação de artigos científicos. Além destes, dissertações, teses, artigos publicados em congressos também foram incorporados quando eram citados de forma recorrente nos primeiros artigos coletados e guardavam relação com tema aqui tratado. A partir dessa revisão realizamos uma sistematização do tema, propondo um panorama geral de pesquisas científicas que tratam do Airbnb, seus impactos e também sobre regulação do agente em âmbito internacional. Essa visualização está baseada na análise das regulações originalmente promovida pelos autores revisados. As legislações brasileiras (até setembro de 2019), por sua vez, foram identificadas através de pesquisa no buscador Google pelos termos "regulação + Airbnb", "lei + Airbnb", "proibição + Airbnb", tendo sido identificadas regulações vigentes e revogadas em nível municipal e projetos de lei em nível federal. A análise desses marcos legais foi empreendida de forma inédita neste trabalho e comparada em termos de objetivos pretendidos com a avaliação dos marcos internacionais. A Figura 1 é um esquema que resume a metodologia aplicada. 
Figura 1: Delineamento da metodologia

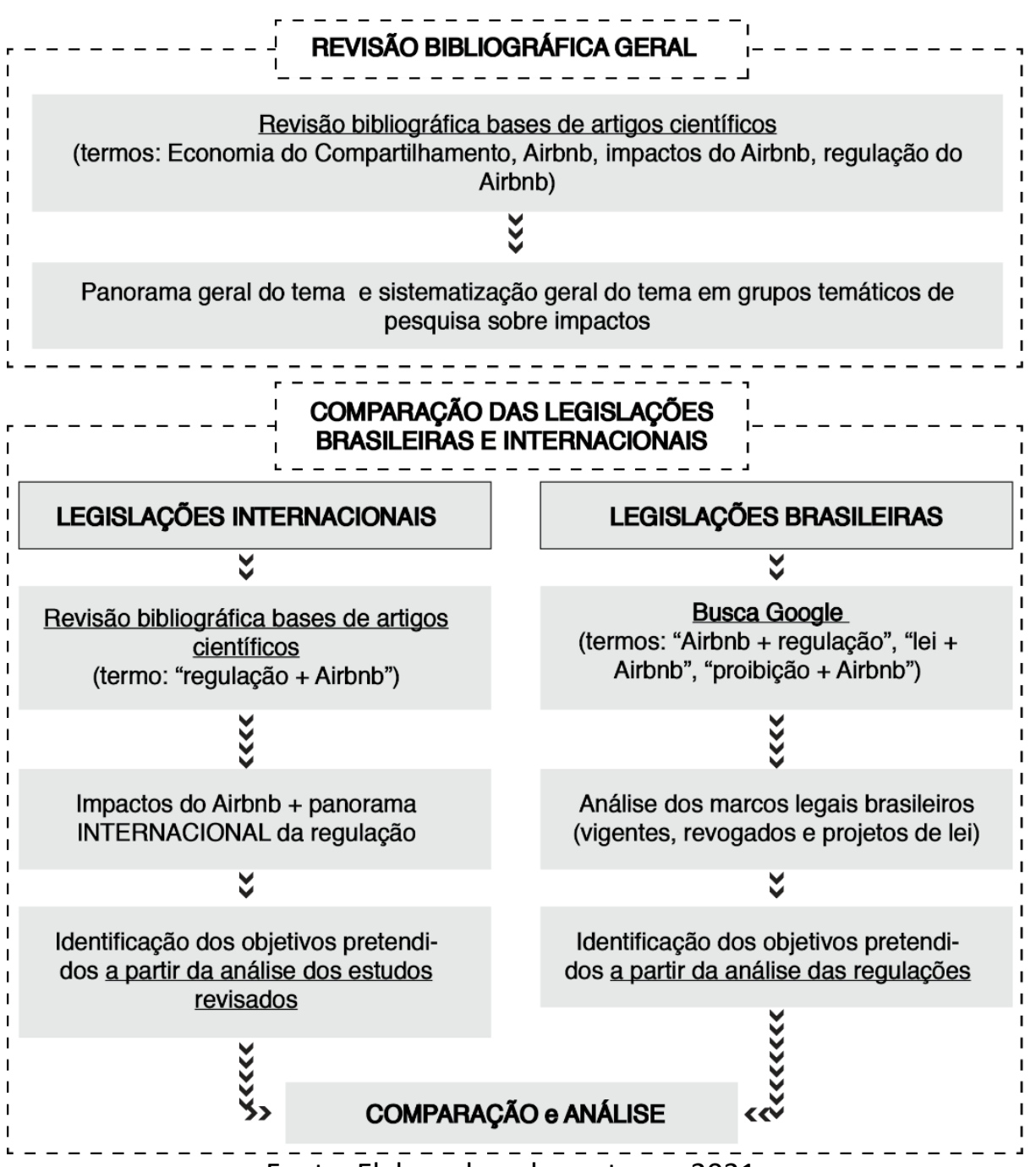

Fonte: Elaborado pelos autores, 2021.

O artigo está estruturado em cinco seções. Na primeira seção discutimos o fenômeno da Economia do Compartilhamento e a necessidade de sua regulação; em seguida discutimos o porquê de regular o Airbnb, tendo como pano de fundo seus impactos urbanos; a regulação desse agente como tem sido abordada no mundo é discutida na terceira seção, e no Brasil na quarta. Ao final concluímos como as legislações brasileiras se inserem no panorama internacional e quais questões elas, intencionalmente ou não, tratam em seus dispositivos. 


\section{REGULAÇÃO DA ECONOMIA DO COMPARTILHAMENTO}

A Economia do Compartilhamento é um fenômeno que tem crescido recentemente (SCHOR, 2019) e alterado a maneira como se tem utilizado uma série de serviços, passando pelo transporte individual, entrega de comida, mercado de compra e venda de roupas, uso de ferramentas, serviço de buffet, entre outros (SLEE, 2017). Apesar de não haver uma unanimidade entre os autores do conceito de Economia do Compartilhamento, o termo tem sido utilizado para definir redes online de usuários distribuídas que compartilham ou trocam ativos, que na ausência dessa mesma rede, estariam subutilizados ou ociosos (KOOPMAN; MITCHEL; THIERER, 2015; KATZ, 2015; SHEPARD; UDELL, 2016; QUATTRONE et al., 2016).

A exemplo de empresas que se inserem dentro desse modelo de negócios pode-se citar Uber, no setor de transportes, TaskRabbit, através do qual pode-se contratar prestações de serviços diversos, pequenos reparos, 1000 tools para aluguel de ferramentas, Eatwith onde usuários podem compartilhar refeições e "experiências culinárias", entre outras tantas iniciativas, além do próprio Airbnb (SLEE, 2017).

$\mathrm{Na}$ medida em que apresentam formas inovadoras de prover serviços tradicionalmente oferecidos por outras iniciativas historicamente estabelecidas (KAPLAN; NADLER, 2017; FERRERI; SANYAL, 2018), as iniciativas inseridas dentro da Economia do Compartilhamento entram em conflito com estas iniciativas tradicionais porque estão isentas de regulação apropriada. Mais do que isso, apesar de estarem postas como concorrentes, muitas vezes, no mesmo mercado (Uber x Táxis; Airbnb x Hotéis e pousadas), a regulação deve partir de premissas distintas das regulações tradicionais, porque as complexidades da maneira como operam essas empresas são diferentes das iniciativas tradicionais (KATZ, 2015; SILVA; PAIVA; DINIZ, 2017).

Slee (2017) aponta a Economia do Compartilhamento muito mais como uma nova roupagem para um pequeno grupo de empresas de tecnologia com ganhos bilionários do que como um "movimento" pelo ato de compartilhar

Se a Economia do Compartilhamento é um movimento pela desregulação. Grandes instituições financeiras e fundos influentes de capital de risco estão vislumbrando, com ela, uma oportunidade para desafiar as regras formuladas pelos governos municipais democráticos ao redor do mundo - e para remodelar as cidades de acordo com seus interesses (SLEE, 2017, p. 48) 
Diferentemente de iniciativas da Economia do Compartilhamento que buscam a cooperação e trocas voluntárias (bibliotecas comunitárias, banco de tempo, de sementes, etc.) que não buscam o lucro, as empresas com fins lucrativos estão interessadas na maximização de ativos, (SCHOR, 2017). Segundo essa mesma autora, quanto mais transações entre os usuários maior é o lucro capturado pela empresa, sendo esse o caso do Uber e do Airbnb, avaliados em US\$18 bilhões e US\$10 bilhões de dólares.

A desregulação seria de interesse dessas empresas, conforme anteriormente explicitado por Slee (2017) porque as deixa operando livremente, sem que paguem taxas, impostos e/ou enfrentem limitações urbanísticas. Toma-se como discurso sedutor e justificativo o fato de que estão baseadas no compartilhamento e na cooperação "inofensiva" entre usuários. Dessa forma, passam por despercebidos os possíveis impactos que essas empresas podem impor a coletividade e que, na ausência de regulação, tornam-se difíceis de serem mitigados.

\section{POR QUE REGULAR O AIRBNB?}

Conforme as análises a seguir relatadas, a presença do Airbnb tem contribuído com benefícios para as cidades e para os usuários no mundo todo. A plataforma amplia a possibilidade de muitos proprietários ampliarem sua renda através do aluguel, injeta capital no turismo local (DINATALE; LEWIS; PARKER, 2018), promove encontros entre pessoas desconhecidas (BELARMINO; KOH, 2020) e diversifica as opções de hospedagem porque não necessariamente tem localizações que coincidem com as dos hotéis na cidade (QUATTRONE et al., 2016; GURRAN; PHIBBS, 2017; GUTIÉRREZ, 2017). Com o cuidado de não invalidar esses benefícios aqui, no entanto, interessa-nos despir desse olhar unidirecional e visualizar também as externalidades negativas geradas pelo Airbnb que, muitas vezes não são objeto de regulação concernente.

É possível sistematizar três grupos de impactos notados no espaço urbano: [1] Impactos no mercado de hospedagem; [2] Impactos no mercado imobiliário e [3] Impactos na qualidade de vida da vizinhança.

Quanto aos impactos no mercado de hospedagem, o Airbnb amplia o leque de opções de hospedagem para o turista, gerando uma concorrência antes inexistente com as grandes cadeias hoteleiras. O valor de mercado do Airbnb já superou o de grandes cadeias hoteleiras como o Marriott International (SHEPARD; UDELL, 2016). 
Em Los Angeles, investidores têm convertido edifícios inteiros em unidades para aluguel de curta temporada (LEE, 2016). Estudos independentes apontam que o crescimento do Airbnb está relacionado com redução dos lucros - ainda que tímida, na casa dos decimais - do ramo hoteleiro, especialmente os pequenos hotéis (ZERVAS; PROSERPIO; BYERS, 2016; GURRAN; PHIBBS, 2017; NASCIMENTO, 2018). O Airbnb consegue responder muito rapidamente ao crescimento da demanda por acomodação, visto que utiliza unidades pré-existentes em contraste com o ramo hoteleiro que depende de construir novas unidades para responder a essa necessidade (ZERVAS; PROSERPIO; BYERS, 2016).

Mesmo com a expansão do Airbnb, as cadeias hoteleiras têm tido suas maiores taxas de ocupação nos últimos anos (THOMPSON, 2018), pelo menos nos EUA que é o maior mercado do site. Ainda segundo esse autor, jovens millenials e pessoas abaixo de 35 anos são os maiores usuários da plataforma, diferente de viajantes de negócios que continuam utilizando os hotéis como antes. Os mais prejudicados são pequenos hotéis, pousadas e pensões, que perdem competitividade frente ao Airbnb, porque precisam atender à uma série de legislações de incêndio e segurança as quais são evadidas pelos anfitriões do site de hospedagem (SLEE, 2017, p. 71).

No segundo grupo, avaliam-se os impactos do Airbnb no mercado de imóveis. Pesquisadores no mundo inteiro têm diagnosticado cenários que indicam o papel do Airbnb como um real agente que tem interferido nas dinâmicas do espaço urbano e do mercado de imóveis. Se a dispersão das unidades disponíveis para aluguel por toda a cidade contribui para a ampliação das possibilidades de hospedagens como colocado anteriormente, em contrapartida imprime especulação imobiliária em áreas que antes não conviviam com essa realidade (GUTIÉRREZ et al., 2017).

Em Boston, há uma correlação entre a redução de número de unidades disponíveis para aluguel convencional com o aumento das unidades do Airbnb, indicando uma alta que chega a 3,1\% nas zonas de maior concentração (MERANTE; HORN, 2017, p. 19). Em Los Angeles, os aluguéis de curta temporada removeram 7316 unidades do mercado da cidade em 2014. Uma redução de 1\% das unidades residenciais no mercado está relacionada à um aumento em $7,3 \%$ dos preços dos aluguéis (LEE, 2016, p. 239). Em Nova York, estudos independentes demonstraram impactos na alta de preços (SHEPARD; UDELL, 2016) e de gentrificação (WACHSMUTH; WEISLER, 2018).

O Airbnb tem contribuído para a redução de oferta de imóveis para aluguel convencional porque muitos proprietários têm preferido colocar seus imóveis para aluguel por curtas temporadas do que disponibilizá-los em contratos de longo prazo. DiNatale, Lewis e Parker (2018) ao avaliar a receita anual de aluguéis convencionais e através do Airbnb, em cidades do estado do Oregon, EUA, constatam que a receita do Airbnb é superior em 7 das 10 cidades analisadas. 
Ainda entre impactos no espaço urbano, a seguir pontuamos as externalidades na qualidade de vida das vizinhanças. Como já colocado anteriormente, a gentrificação é o principal deles, todavia outros impactos que não são possíveis de serem objetivamente quantificados também foram relatados pela literatura revisada. Dentro dos edifícios e condomínios a alta rotatividade de "moradores" pode gerar um sentimento de insegurança nos reais moradores de longa permanência (FERRERI; SANYAL, 2018) e de fato uma exposição a riscos, visto que os anunciantes no Airbnb não podem garantir que os locadores de seus imóveis não têm intenções de promover ilicitudes ${ }^{3}$. Além disso, em razão de ser apenas um morador provisórios, os turistas muitas vezes lidam com o espaço coletivo sem o mesmo cuidado que os reais moradores. No Rio de Janeiro, uma decisão judicial proibiu um morador de alugar seu imóvel por períodos menores de trinta dias por insatisfação dos outros moradores com o "comportamento nocivo" dos turistas que alugavam via Airbnb (RIBAS, 2018). Na escala da cidade pode implicar em disputas entre os moradores e os turistas por maior tranquilidade em regiões previamente residenciais (DINATALE; LEWIS; PARKER, 2018; WEGMANN; JIAO, 2017).

Assim como estudos de caráter acadêmico têm identificado a reverberação do Airbnb no espaço urbano, manchetes de jornais pelo mundo engrossam a noção de que a plataforma realmente tem gerado incômodo em realidades urbanas distintas. Na tabela 1 reúnem-se uma série de manchetes que demonstram a relação conflituosa de cidades, especialmente europeias, com o Airbnb.

Tabela 1: Manchetes ilustrativas da relação do Airbnb com variadas cidades pelo mundo

\begin{tabular}{|c|c|c|c|c|}
\hline \multicolumn{5}{|c|}{ (continua) } \\
\hline Ano & Manchete & Cidade(s) & Principal questão abordada & Jornal \\
\hline 2016 & $\begin{array}{l}\text { Berlim reforça cerco contra } \\
\text { aluguel por temporada em } \\
\text { sites como Airbnb }\end{array}$ & Berlim & $\begin{array}{l}\text { Proibição da plataforma em face } \\
\text { à escassez de unidades para } \\
\text { aluguel convencional e } \\
\text { consequente alta de preços }\end{array}$ & $\begin{array}{l}\text { Folha } \\
\text { de São } \\
\text { Paulo }\end{array}$ \\
\hline 2016 & $\begin{array}{c}\text { Airbnb começa a ceder a } \\
\text { exigências legais de cidades } \\
\text { onde atua }\end{array}$ & $\begin{array}{l}\text { Londres e } \\
\text { Amsterdã }\end{array}$ & $\begin{array}{l}\text { Regulação em face a alta dos } \\
\text { aluguéis }\end{array}$ & $\begin{array}{l}\text { Gazeta } \\
\text { do } \\
\text { Povo/ } \\
\text { Brasil }\end{array}$ \\
\hline 2016 & $\begin{array}{l}\text { Barcelona multará Airbnb } \\
\text { em } 600.000 \text { euros por } \\
\text { anunciar apartamentos sem } \\
\text { licenças }\end{array}$ & Barcelona & $\begin{array}{l}\text { Regulação em face a alta dos } \\
\text { aluguéis, incômodo às } \\
\text { vizinhanças e saturação do } \\
\text { espaço público }\end{array}$ & $\begin{array}{l}\text { Gazeta } \\
\text { do } \\
\text { Povo }\end{array}$ \\
\hline
\end{tabular}

\footnotetext{
${ }^{3} \mathrm{O}$ portal Airbnb Hell dedica-se exclusivamente a reunir relatos de usuários do Airbnb que passaram por golpes e fraudes em transações na plataforma. Disponível em: https://www.airbnbhell.com, acesso em 22 fev. 2021.
} 


\begin{tabular}{|c|c|c|c|c|}
\hline \multirow[b]{2}{*}{ Ano } & \multirow[b]{2}{*}{ Manchete } & \multirow[b]{2}{*}{ Cidade(s) } & \multicolumn{2}{|c|}{ (conclusão) } \\
\hline & & & Principal questão abordada & Jornal \\
\hline 2018 & $\begin{array}{c}\text { Cidades europeias saturadas } \\
\text { de turistas se unem contra o } \\
\text { Airbnb }\end{array}$ & $\begin{array}{c}\text { Madrid, } \\
\text { Barcelona, } \\
\text { Bruxelas, Paris, } \\
\text { Cracóvia, Viena } \\
\text { e Reykjavik }\end{array}$ & $\begin{array}{l}\text { Exigência de acesso aos dados dos } \\
\text { clientes da plataforma }\end{array}$ & $\begin{array}{l}\text { El } \\
\text { País }\end{array}$ \\
\hline 2018 & $\begin{array}{l}\text { Palma é a primeira cidade } \\
\text { espanhola a proibir aluguel } \\
\text { turístico, como Airbnb }\end{array}$ & $\begin{array}{l}\text { Palma de } \\
\text { Mallorca, } \\
\text { Espanha }\end{array}$ & $\begin{array}{c}\text { Escassez de unidades para aluguel } \\
\text { convencional e consequente alta } \\
\text { de preços }\end{array}$ & $\begin{array}{l}\text { El } \\
\text { País }\end{array}$ \\
\hline 2018 & $\begin{array}{l}\text { Metrópoles turísticas limitam } \\
\text { o avanço do Airbnb }\end{array}$ & $\begin{array}{l}\text { Barcelona, } \\
\text { Paris, Amsterdã } \\
\text { e Berlim }\end{array}$ & $\begin{array}{l}\text { Marcos regulatórios instituídos } \\
\text { pelas cidades para controle do } \\
\text { Airbnb }\end{array}$ & $\begin{array}{l}\text { El } \\
\text { País }\end{array}$ \\
\hline 2018 & $\begin{array}{l}\text { O que o Airbnb realmente faz } \\
\text { com uma vizinhança } \\
\text { (tradução nossa) }\end{array}$ & $\begin{array}{l}\text { Amsterdã, } \\
\text { Barcelona, } \\
\text { Berlim, Londres, } \\
\text { Palma, New } \\
\text { York City, Paris, } \\
\text { San Francisco, } \\
\text { Cingapura, } \\
\text { Tóquio }\end{array}$ & $\begin{array}{l}\text { Impactos e diferentes abordagens } \\
\text { da regulação do Airbnb pelo } \\
\text { mundo }\end{array}$ & BBC \\
\hline 2019 & $\begin{array}{l}\text { Câmara do Rio analisa se } \\
\text { projeto para cobrar ISS de } \\
\text { Airbnb segue adiante }\end{array}$ & Rio de Janeiro & $\begin{array}{c}\text { Cobrança de imposto dos } \\
\text { usuários do Airbnb para } \\
\text { equiparação de concorrência com } \\
\text { hotéis }\end{array}$ & Extra \\
\hline 2019 & $\begin{array}{l}\text { Boom de propriedades em } \\
\text { Atenas: Gregos vão embora a } \\
\text { medida em que preços } \\
\text { sobem (tradução nossa) }\end{array}$ & Atenas & $\begin{array}{l}\text { Altas dos preços em face a } \\
\text { investidores estrangeiros que } \\
\text { compram apartamentos para } \\
\text { investimento imobiliário via } \\
\text { Airbnb }\end{array}$ & BBC \\
\hline
\end{tabular}

Fonte: Elaborada pelos autores a partir das notícias elencadas, 2019.

(As notícias foram coletadas através do buscador Google usando os termos "Airbnb", "regulação", "impactos" em português inglês e espanhol, na aba notícias)

Com essa extensão e constante expansão, o Airbnb se coloca no mercado de aluguéis de curta temporada oferecendo benefícios para os usuários: mais opções de hospedagem, melhores preços e oportunidade complementar a renda para os proprietários (AIRBNBa, 2018), porém está em concorrência com o mercado convencional de hospedagem que tem obrigações legais que são evadidas pelo site: limitações de zoneamento, pagamento de encargos trabalhistas, obrigações de segurança, recolhimento de taxas municipais. No mercado de aluguéis conforme demonstrado, pode contribuir para processo de gentrificação e aumento do preço dos aluguéis e consequente esvaziamento de moradores locais das regiões com maior concentração de unidades.

Apesar de todo o discurso de "cuidar do planeta, preparar um futuro melhor para aqueles em necessidade e proteger o meio ambiente, liberando o potencial de compartilhar de todos" (PEOPLE..., 
2019), as iniciativas da Economia do Compartilhamento impõem externalidades às cidades. Estas são incorporadas pela coletividade das cidades que ficam cada vez mais expostas na medida em que avança, como caso do Airbnb. Não se trata de banir as iniciativas da Economia do Compartilhamento ou o próprio Airbnb, até porque essas empresas vieram para ficar (KATZ, 2015), pois representam possibilidades de obtenção de renda através de ativos que antes estariam subutilizados, resultam portanto em níveis cada vez mais altos de atividade econômica e uso de bens e habilidades próximos de sua plena capacidade (SUNDARARAJAN, 2018). Por outro lado, a regulação deve ser vista como uma alternativa possível para colocá-las em concorrência justa com outras iniciativas semelhantes tradicionalmente estabelecidas; mais do que isso, buscar impulsionar seus benefícios e também mitigar seus impactos negativos (WEGMANN; JIAO, 2017; SCHOR, 2017).

\section{REGULANDO O AIRBNB NO MUNDO}

$\mathrm{Na}$ busca de controlar e/ou mitigar os impactos descritos acima, especialmente a ameaça à permanência dos residentes locais, as cidades têm aplicado regras à presença do Airbnb. Dados os desafios de regular empresas que operam na Economia do Compartilhamento as cidades se valem de estratégias e abordagens distintas. Apesar das empresas da Economia do Compartilhamento estarem muitas vezes postas como concorrentes com empresas "tradicionais" (Uber x Táxis; Airbnb x Hotéis e pousadas), a regulação deve partir de premissas distintas das regulações tradicionais, porque as maneiras como operam essas empresas são diferentes (KATZ, 2015; SILVA; PAIVA; DINIZ, 2017).

Em entrevista concedida ao Wall Street Journal em janeiro de 2014, Brian Chesky, co-fundador do Airbnb, afirma que "existem leis que foram criadas para negócios e existem outras para pessoas. 0 que a Economia do Compartilhamento fez foi criar uma terceira categoria: pessoas como negócios" (KESSLER, 2014 apud KAPLAN; NADLER, 2017, p. 108). Para Kaplan e Nadler (2017), os marcos regulatórios existentes teriam aplicação pouco clara nesta categoria (KAPLAN; NADLER, 2017). O desafio torna-se ainda maior porque no caso específico do Airbnb, há agentes diversos com interesses distintos e até divergentes, defendendo posições opostas, como ilustrado na Tabela 2. 
Tabela 2: Grupos de interesse envolvidos na regulação do Airbnb

\begin{tabular}{|l|l|l|}
\hline \multicolumn{1}{|c|}{ Agente } & \multicolumn{1}{|c|}{ Interesse } & \multicolumn{1}{c|}{ Objetivo } \\
\hline Indústria hoteleira & $\begin{array}{l}\text { Regras mais rígidas comparadas às } \\
\text { aplicadas aos hotéis e pousadas }\end{array}$ & $\begin{array}{l}\text { Estabelecer concorrência mais } \\
\text { justa com as plataformas }\end{array}$ \\
\hline $\begin{array}{l}\text { Associações de } \\
\text { moradores }\end{array}$ & $\begin{array}{l}\text { Controlar ou reduzir o } \\
\text { desenvolvimento de aluguéis de curto } \\
\text { prazo }\end{array}$ & $\begin{array}{l}\text { Reduzir os incômodos percebidos } \\
\text { na vizinhança }\end{array}$ \\
\hline
\end{tabular}

(conclusão)

\begin{tabular}{|c|c|c|}
\hline Agente & Interesse & Objetivo \\
\hline $\begin{array}{l}\text { Organizações } \\
\text { profissionais de } \\
\text { locadoras de turismo }\end{array}$ & $\begin{array}{l}\text { Opõem-se a qualquer limitação ao } \\
\text { crescimento, mas têm interesse em } \\
\text { regulamentos para os anfitriões } \\
\text { profissionais "ilegais" }\end{array}$ & $\begin{array}{l}\text { Regulamentar o uso das } \\
\text { plataformas como forma legal de } \\
\text { aluguel, possibilitar seu } \\
\text { crescimento e equiparar os } \\
\text { anfitriões profissionais às mesmas } \\
\text { obrigações legais que lhes cabem }\end{array}$ \\
\hline $\begin{array}{l}\text { Associações de } \\
\text { anfitriões } \\
\text { "compartilhadores" }\end{array}$ & $\begin{array}{l}\text { Opõem-se às regras como um } \\
\text { obstáculo ao uso gratuito da } \\
\text { propriedade privada e o direito de } \\
\text { alugar e compartilhar para obtenção } \\
\text { de renda adicional }\end{array}$ & $\begin{array}{l}\text { Liberdade para utilizar sua } \\
\text { propriedade da forma que desejar }\end{array}$ \\
\hline $\begin{array}{l}\text { Promotores da } \\
\text { Economia do } \\
\text { Compartilhamento }\end{array}$ & $\begin{array}{l}\text { Defensores do movimento global de } \\
\text { compartilhar e mobilizar recursos } \\
\text { subutilizados }\end{array}$ & $\begin{array}{l}\text { Incentivar e garantir o direito de } \\
\text { "compartilhar" livremente }\end{array}$ \\
\hline Plataformas & $\begin{array}{l}\text { Evitar regulamentos estritos e } \\
\text { requisitos restritivos }\end{array}$ & $\begin{array}{l}\text { Crescimento e ampliação dos } \\
\text { lucros sem muitos obstáculos }\end{array}$ \\
\hline
\end{tabular}

Fonte: Elaborado pelos autores a partir de Aguilera, Artioli e Colomb (2019b), 2021.

A depender dos tipos e graus de impactos gerados pela plataforma, e também dos benefícios que a cidade deseja incentivar e ou restringir a partir do Airbnb, cada localidade constrói regulações próprias (NIEUWLAND; MELIK, 2018; FURUKAWA; ONUKI, 2019).

O discurso do livre mercado auxilia as empresas da Economia do Compartilhamento, entre elas o Airbnb, a justificar que não há necessidade de regulação pelo fato de que estas seriam supostamente "naturais, politicamente neutras, consensuais e eficientes" (MCKEE, 2017, p. 456, tradução nossa). Segundo Koopman, Mitchel e Thierer (2015) quando a regulação é obsoleta ao lidar com as iniciativas da Economia do Compartilhamento pode acabar por prejudicar os consumidores. A regulação das plataformas da economia colaborativa e do Airbnb não tem precedente no Direito e constitui um desafio por sua peculiaridade (PAYÃO; VITA, 2018). Para esses últimos autores, essa regulação deve ser compatível aos serviços e relações jurídicas, sob pena de gerar mais ineficiência e prejuízo ao desenvolvimento econômico. 
Dois impactos da presença do Airbnb na dinâmica urbana são apontados em debates, reportagens, movimentos sociais e estudos urbanos contemporâneos, mas ainda pouco registrado com pesquisas científicas. O primeiro é a captura dos imóveis disponíveis no mercado de aluguel convencional para o Airbnb, provocando escassez de oferta destes imóveis para os moradores permanentes e aumentando o valor dos mesmos. Consequentemente, uma vez este processo acirrado, desencadeia o segundo impacto da presença do Airbnb na dinâmica urbana: a gentrificação, promovendo expulsão de moradores, alteração de usos tradicionais, turistificação e elitização de bairros inteiros. Gurran, $(2018$, p.301) alerta que em "mercados de moradia com alta demanda, governos municipais e planejadores urbanos precisarão defender a moradia permanente de conversão para acomodações de férias de curta temporada".

De acordo com DiNatale, Lewis e Parker (2018) as cidades têm adotado regulações com limites de concentração de unidades, cumprimento de requisitos específicos, restrição do Airbnb a determinadas áreas através de zoneamento e inspeções às unidades. Coles et al. (2017) pontuam quatro tipos de regulações: banimento, limite de diárias, limites de unidades e regulação localizada por região da cidade (quando dentro de um mesmo município há diferentes abordagens). Uma outra categorização de legislações sugere seis tipos de regulação, segundo suas abordagens: Laissez-faire (sem regulação); Genérica (que não diferencia os tipos de unidade); Orientada pela residência (que restringe anúncios operado por profissionais, que usam imóveis além do seu próprio); Orientada pelo anfitrião (que restringe anúncios em que o proprietário esteja ausente); Híbrida (que tem uma mistura entre tipos, com abordagens diferenciadas por região); e Proibitiva (que impossibilita ou torna muito difícil a atuação das plataformas) (FURUKAWA; ONUKI, 2019). Nieuwland e Melik (2018) também propõem uma classificação das regulações numa escala que varia entre "banimento total" e "Iaissezfaire" (ver Figura 2). A escala é proposta a partir de um olhar sobre 11 cidades, sendo 5 europeias e 6 estadunidenses. 


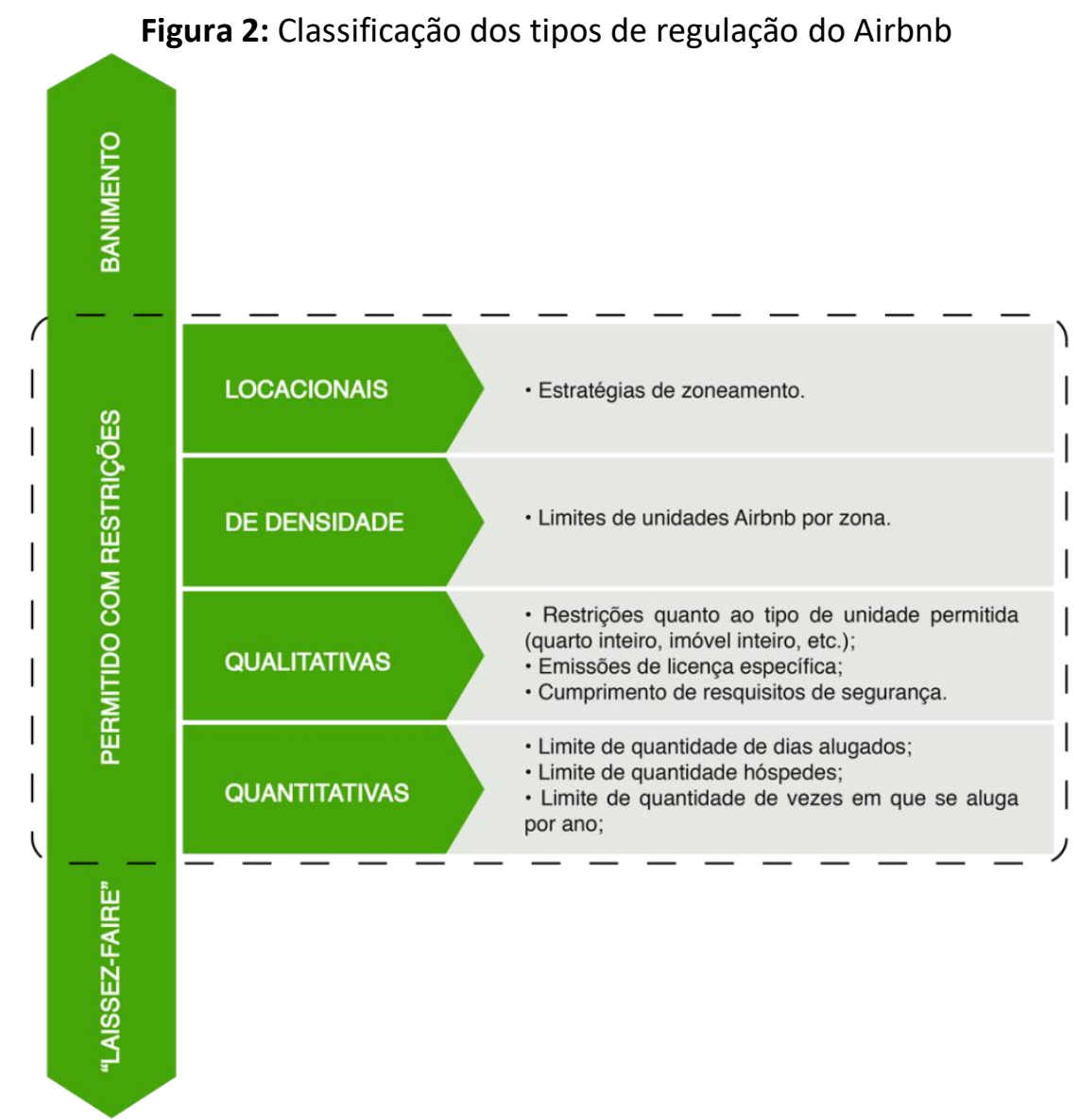

Fonte: Elaborado pelos autores a partir de Nieuwland e Melik (2018), 2021.

A seguir são descritas as regulações de algumas cidades que exemplificam os tipos observados.

Em Nova York, onde há 50.000 anúncios e o Airbnb seria responsável pelo aumento do aluguel em 11\% entre 2009 e 2016, são proibidos os aluguéis de menos de 30 dias sem a presença do proprietário na unidade (BROSSAT, 2019). Fort Lee, New Jersey e Santa Monica, todas nos EUA, também têm abordagem que banem os aluguéis de curta temporada na ausência do proprietário (COLES et al., 2017). Em San Francisco há exigência de registro da unidade e apenas a primeira residência do proprietário pode ser ofertada, sendo que o limite de 30 dias é para o ano inteiro (GURRAN, 2018). Segundo esse autor, Berlim também exige registro e as unidades são sujeitas a taxas como "casas de férias". Ainda em Berlim, uma lei em 2016 permite a residentes alugar apenas partes dos imóveis (MCKEE, 2017). Londres tem uma regulação semelhante a San Francisco, com um limite de 90 dias por ano (FERRERI; SANYAL, 2018) e não permite casas inteiras serem alugadas via plataforma (NIEUWLAND; MELIK, 2018).

Também com estratégia de limitar o número de noites, Amsterdã impõe o máximo de 60 noites, e inclui ainda o requisito de que o proprietário resida na unidade por, pelo menos, 6 meses ao 
longo ano (SLEE, 2017; NIEUWLAND; MELIK, 2018). Essa última estratégia dificulta a conversão do imóvel para uso exclusivo como acomodação no Airbnb.

O Japão tem uma abordagem nacional para a regulação desse tipo de plataforma chamada "minkapu" (BROSSAT, 2019). Há um limite de 180 noites ao longo do ano todo e autoridades municipais exigem identificação dos hóspedes. Podem haver diferenciações a serem definidas pelos poderes locais. Em Kyoto, por exemplo, os aluguéis turísticos só são permitidos na baixa temporada (entre janeiro e março) enquanto que em Tóquio há a proibição da operação em determinados dias da semana e em alguns distritos específicos (BROSSAT, 2019).

Milão, na Itália, submeteu as unidades Airbnb a regras semelhantes à pousadas (bed-andbreakfast), numa aparente tentativa de equiparar a plataforma à esse serviço convencional de hospedagem (AGUILERA; ARTIOLI; COLOMB, 2019a).

O Airbnb apareceu como um novo elemento no fenômeno de expansão turística em Barcelona que já tem um histórico de luta, com forte participação popular, contra externalidades do turismo desde 1992 (AGUILERA; ARTIOLI; COLOMB, 2019a). A cidade estabeleceu uma regulação com o objetivo de "crescimento zero": há uma limitação de número total de 10.000 anúncios, sendo que em se atingindo esse total, somente pode entrar um novo anúncio, caso outro seja desativado (BROSSAT, 2019). Objetiva-se, com o auxílio de um sistema de zoneamento, reduzir o número de unidades em determinadas regiões centrais mais pressionadas, substituindo por um aumento modesto em outras áreas (AJUNTAMENT..., 2017; AGUILERA; ARTIOLI; COLOMB, 2019b). Essa estratégia de utilizar o zoneamento como ferramenta também aparece em Chicago (COLES et al., 2017) e Nova Orleans (HOLM, 2020). Nessa última, o zoneamento determina três tipos de unidades: "acessória" = em que o anfitrião deve estar presente no local; "temporária" = máximo de 90 dias por ano; "comercial" = sem limites de dias, mas fora de zonas residenciais (HOLM, 2020).

A cidade de Paris por sua vez tem, além do registro obrigatório, um limite de 120 dias por ano para aluguel em curta temporada. Ultrapassado esse teto, a unidade é denominada pela legislações municipais não mais como unidade habitacional, mas como um estabelecimento comercial. Aplica-se então a "regra de compensação": para cada metro quadrado que foi convertido em unidade comercial, o proprietário deve destinar a mesma metragem em habitação social - ou o dobro da metragem, caso seja habitação privada - em outra região da cidade (AGUILERA; ARTIOLI; COLOMB, 2019a; BROSSAT, 2019). Segundo os autores, os multiproprietários não são permitidos na capital francesa e estão sujeitos a multas de 50.000 euros. A cidade de Lyon, também na França, tem legislação semelhante: exige o registro e aplica a regra de compensação (BROSSAT, 2019). 
Desde 2018, o Airbnb foi banido através de legislação municipal na cidade de Anaheim, na região metropolitana de Los Angeles (NIEUWLAND; MELIK, 2018). A cidade é sede do resort Disneyland na Califórnia, EUA.

Para Nieuwland e Melik (2018), as abordagens se prestam aos objetivos da cidade. As autoras observam que as regulações visam atender a dois objetivos: escassez de habitação a preços razoáveis e alterações na vizinhança. Constatam também que a principal preocupação das cidades não é o caráter inicial da plataforma de compartilhar a residência, mas a tendência do crescimento de unidades com objetivos claramente comerciais (NIEUWLAND; MELIK, 2018). Mesmo que haja esse pano de fundo comum, as ênfases diferem de cidade para cidade.

Em cidades como Denver, onde o turismo está ainda em fase de crescimento, o Airbnb provavelmente será visto como complementar à oferta atual de quartos de hotel, enquanto que em cidades com uma indústria do turismo mais saturada, o Airbnb pode ser considerado como concorrência direta. (NIEUWLAND; MELIK, 2018, p. 12, tradução nossa)

As medidas impostas pelas cidades estão guiadas por suas intenções com os marcos regulatórios e os agentes envolvidos. Isso explica porque, mesmo que semelhantes, há ênfases distintas nas regulações: restrições ou banimento por zonas, por época do ano ou da semana, restrições de multiproprietários ou não e dos tipos imóveis permitidos ou não.

Para além das limitações de dias, registros e taxas, Paris, Lyon e Barcelona têm regulações que, por sua natureza, têm maior potencial de controlar as externalidades do Airbnb no acesso à moradia. Barcelona porque tem um limite de número de anúncios e, portanto coloca um teto "sustentável" do Airbnb e as cidades francesas porque associam a expansão desse agente com a compensação com unidades habitacionais na mesma proporção. Teoricamente, essas regulações seriam mais eficientes e teriam maior controle sobre o crescimento e os impactos da plataforma.

A partir da revisão bibliográfica e os estudos revisados sobre regulação do Airbnb, apresentamse na Tabela 3 as abordagens gerais das legislações identificados internacionalmente, em resumo. 
Tabela 3: Abordagens gerais das regulações identificadas internacionalmente

(continua)

\begin{tabular}{|c|c|}
\hline Cidade & Abordagem geral da legislação \\
\hline Amsterdã (Países Baixos) & $\begin{array}{l}\text { Limite de aluguel de } 60 \text { noites por ano } \\
\text { Proprietário deve residir no imóvel por, pelo menos, } 6 \text { meses do } \\
\text { ano }\end{array}$ \\
\hline Anaheim (EUA) & Banimento total \\
\hline Barcelona (Espanha) & $\begin{array}{l}\text { Limite de } 10.000 \text { anúncios } \\
\text { Limite por zonas específicas }\end{array}$ \\
\hline Berlim (Alemanha) & $\begin{array}{l}\text { Registro da unidade } \\
\text { Pagamento de taxas }\end{array}$ \\
\hline Chicago (EUA) & Limite por zonas específicas \\
\hline Fort Lee (EUA) & Banimento na ausência do proprietário \\
\hline Kyoto (Japão) & $\begin{array}{l}\text { Limite de } 180 \text { noites por ano } \\
\text { Identificação dos hóspedes } \\
\text { Banimento durante toda a alta temporada }\end{array}$ \\
\hline Londres (Reino Unido) & $\begin{array}{l}\text { Limite de aluguel de } 90 \text { dias por ano } \\
\text { Banimento do aluguel de imóveis inteiros }\end{array}$ \\
\hline Lyon (França) & $\begin{array}{l}\text { Emissão de licença } \\
\text { Regra de compensação (um imóvel convertido ao Airbnb deve } \\
\text { ser compensado pela oferta de outro imóvel construído para o fim } \\
\text { de habitação) }\end{array}$ \\
\hline Milão (Itália) & $\begin{array}{l}\text { Equiparação às mesmas regras de pequenas pousadas (bed-and- } \\
\text { breakfasts) }\end{array}$ \\
\hline New Jersey (EUA) & Banimento na ausência do proprietário \\
\hline Nova Orleans (EUA) & Limite por zonas específicas \\
\hline Nova York (EUA) & Banimento para mais de 30 dias \\
\hline Paris (França) & $\begin{array}{l}\text { Emissão de licença } \\
\text { Limite de } 90 \text { dias por ano } \\
\text { Proibição de multiproprietários } \\
\text { Regra de compensação (um imóvel convertido ao Airbnb deve } \\
\text { ser compensado pela oferta de outro imóvel construído para o fim } \\
\text { de habitação) }\end{array}$ \\
\hline San Francisco (EUA) & $\begin{array}{l}\text { Registro da unidade } \\
\text { Limite de aluguel de } 30 \text { dias por ano } \\
\text { Aluguel apenas da primeira residência }\end{array}$ \\
\hline & (conclusão) \\
\hline Cidade & Abordagem geral da legislação \\
\hline Santa Monica (EUA) & Banimento na ausência do proprietário \\
\hline Tóquio (Japão) & $\begin{array}{l}\text { Limite de } 180 \text { noites por ano } \\
\text { Identificação dos hóspedes } \\
\text { Banimento em determinados dias da semanas } \\
\text { Banimento em determinadas áreas da cidade }\end{array}$ \\
\hline
\end{tabular}

Fonte: Elaborado pelos autores a partir de Coles et al. (2017), McKee (2017), Gurran (2018), Ferreri e Sanyal (2018), Nieuwland e Melik (2018), Brossat (2019) e Holm (2020), 2021. 
Avaliando os impactos e concentrações de unidades Airbnb em 5 cidades dos EUA (Washington, Austin, Chicago, San Francisco e Boston), Wegmann e Jiao (2017) sugerem 4 princípios guias para o estabelecimento de legislações concernentes ao Airbnb: [1] Web-scrapping (ferramenta computacional de coleta de dados em websites) como ferramenta de monitoramento do avanço do Airbnb nas cidades, enquanto o site não disponibiliza esses dados para as autoridades; [2] Limitações de quantidade de unidades por zonas da cidade, visando aliviar escassez de habitação em bairros que tem maior interesse turístico e, transferindo essas permissões para outros bairros que poderiam se beneficiar do uso turístico; [3] Criação de grupo exclusivamente dedicado ao monitoramento nos órgãos públicos, financiado por fundo criado através da cobrança de licenças e [4] Distinção normativa entre proprietários de imóveis que alugam uma parte do imóvel ou mesmo o imóvel inteiro ocasionalmente daqueles proprietários que utilizam o Airbnb como um intermediário para operações comerciais com vários imóveis, preferencialmente banindo esse tipo de prática.

Há uma dificuldade de se confirmar o cumprimento das regulações porque o Airbnb não fornece para as autoridades locais os dados dos hóspedes e anfitriões (GUTTENTAG, 2019). O Procurador da cidade de Nova York instaurou uma intimação ao Airbnb para que liberasse os dados das unidades para as autoridades locais, sendo que o pedido precisou tramitar até a Suprema Corte Americana para que fossem por fim liberados os dados para o poder público (SLEE, 2017; WACHSMUTH; WEISLER, 2018).

De toda forma, o que se percebe é um esforço das cidades em regular o Airbnb de modo a colher os benefícios, mas ao mesmo tempo conter as externalidades negativas (SCHOR, 2017). A associação de estratégias de tipologias diferentes - locacionais, com eventual banimento em algumas zonas, de densidade, quantitativas, também com eventual banimento por tipo de unidade e qualitativas - também é uma constante, conforme Nieuwland e Melik (2018). Ainda segundo estas últimas, de modo geral, as abordagens buscam principalmente a garantia de acesso à habitação a preços acessíveis, evitando processos de gentrificação causados pela plataforma e a segurança dos usuários.

O acesso aos dados das unidades disponíveis para locação, tipo (imóvel inteiro, quarto inteiro, quarto compartilhado, acampamento, chalé etc.), quantidade, espraiamento pela malha urbana é peça-chave para se formule regulações adequadas, justamente porque são eles que vão indicar para as autoridades municipais os padrões de ocupação da plataforma na malha urbana e guiar a atuação das políticas públicas. Como o Airbnb utiliza imóveis de terceiros em suas operações, essa flutuação de unidades está sujeita a mudanças o tempo todo, o que torna o acompanhamento desses dados de maneira sistêmica essencial. 


\section{REGULANDO O AIRBNB NO BRASIL}

No Brasil, duas cidades foram pioneiras na criação de leis para regulação dos aluguéis de curta temporada via Airbnb, são elas Caldas Novas/GO e Ubatuba/SP. Caldas Novas é uma cidade no interior de Goiás, com população estimada em 91.162 habitantes (ESTIMATIVAS..., 2019). Tem forte apelo turístico em função das águas termais. Conta com um total de 77 estabelecimentos de hospedagem, com 30.780 leitos (NÚMERO..., 2016). Uma média de 0,34 leito/habitante, sendo que média brasileira é de 0,01 leito/habitante e do estado goiano é de 0,02 leito/habitante (NÚMERO..., 2016; ESTIMATIVAS..., 2019).

Caldas Novas foi a primeira do Brasil a instituir legislação específica para o Airbnb. Em 2017, institui a Lei Complementar Municipal no 99/2017 criando dispositivos para regulação de aluguéis de curta temporada de até 90 dias contínuos. Sabe-se que aluguéis em períodos maiores configuram aluguéis de longa temporada que são regidos na legislação brasileira pela Lei Federal no 8.245/1991. A principal obrigação para o proprietário do imóvel disponibilizado no site é de emitir uma licença para operação. A lei estabelece também obrigações para o proprietário de recolher uma taxa anual de funcionamento, ISS (Imposto Sobre Serviços de Qualquer Natureza) calculado sobre a diária média do imóvel, informar quantidade de diárias comercializadas, o preço médio cobrado e os dados gerais e de origem dos hóspedes, numa plataforma que seria criada posteriormente (CALDAS NOVAS, 2017). Além disso obriga adequações às regras do condomínio em que o imóvel se encontra e adequações sanitárias conforme a Lei Federal no 11.771 - Política Nacional do Turismo.

A Lei Municipal de Caldas Novas estabelece também que aqueles que não cumprem com a legislação estão sujeitos à advertência e multa de $\mathrm{R} \$ 1.000,00$ e cancelamento da licença, sendo que o valor arrecadado é destinando aos Fundos de Turismo da Cidade de Caldas Novas e Fundo de Aparelhamento e Modernização Fiscal do município de Caldas Novas, esse último sido criado por essa lei.

Ubatuba, cidade no litoral do estado de São Paulo, também com forte caráter turístico que também possui uma norma sobre o funcionamento do Airbnb. Tem uma população, segundo estimativa do IBGE em 2019, de 90.799 habitantes e 194 estabelecimentos de hospedagem com 12.596 leitos (NÚMERO..., 2016), sendo então uma média de 0,14 leito/habitante. A média do estado de São Paulo é, tal como a brasileira, de 0,01 leito/habitante (NÚMERO..., 2016; ESTIMATIVAS..., 2019). A cidade tem um histórico mais controverso no processo de regulamentação do Airbnb, porque chegou 
também a ter uma legislação municipal em 2017, que foi revogada e substituída por nova versão em 2019.

A primeira norma, editada em 2017, é a Lei Municipal de 4.050/2017. Esse marco estabeleceu que o proprietário deveria constituir empresa jurídica para administração do empreendimento, habilitar cadastro nacional junto ao Ministério da Fazenda, realizar cadastro junto ao Ministério do Turismo na categoria Cama \& Café. Além disso, cumprir exigências do Corpo de Bombeiros, Vigilância Sanitária e Código Civil Brasileiro. O limite de diárias contínuas seria de quarenta e cinco. Assim como em Caldas Novas, exigia também consonância como condomínio em que o imóvel está localizado e emissão de licença pelo município. A multa prevista no descumprimento recaía sobre a agência que intermediasse a operação, ou seja o Airbnb. A lei foi revogada em 25 de Janeiro de 2019 (UBATUBA, 2019) depois que moradores se organizaram e acionaram o Ministério Público Estadual apontando que havia um lobby do mercado hoteleiro que se beneficiava da criação da nova lei, e que esta seria inconstitucional ao tornar o proprietário que alugasse seu imóvel no Airbnb um prestador de serviço (BUONO, 2018). O Ministério Público acatou a requisição e nova lei foi aprovada em 2019.

Na Lei Municipal № 4.140/2019, permanece o cadastro obrigatório (Cadastro Municipal de Contribuintes), que implica em pagamento de ISS e o respeito às regras sanitárias e de saúde pública. O marco legal estabelece ainda que o proprietário deve observar os direitos do consumidor e manter livro de reclamações na propriedade. A lei prevê que a operação do Airbnb deve estar em consonância com as regras do loteamento em que se encontra. A não observância do estabelecido pela lei resulta em advertência e multa. O cancelamento da licença de operação não está previsto em lei (UBATUBA, 2019).

NO âmbito federal, dois projetos de lei se destacam. O primeiro é o PL № 748/2015, de autoria do Senador Federal Ricardo Ferraço (PSDB-ES), que propunha a alteração da Lei Federal no 8.245/1991 (Lei do Inquilinato) que trata do aluguel de imóveis urbanos. No seu artigo 48, a Lei Federal estabelece as condições para aluguel de temporada, sendo necessariamente inferior a 90 dias, e não prevê o aluguel através de sítio eletrônico. 0 projeto mantinha os 90 dias e sugeria então a alteração do parágrafo único e inclusão de dois parágrafos:

Art. 1 O 0 art. 48 da Lei no 8.245, de 18 de outubro de 1991, passa a vigorar com as seguintes alterações:

§1ㅇ No caso de a locação envolver imóvel mobiliado, constará do contrato, caso o locatário solicite, a descrição dos móveis e utensílios que o guarnecem, bem como o estado em que se encontram. [...]

$\S 2$ ㅇao descaracterizam a locação para temporada:

I - O oferecimento de imóveis residenciais para locação, em todo ou em parte, por meio de sítios eletrônicos ou aplicativos, observados o disposto no caput; 
II - A cobrança, em apartado, de valores como indenização das despesas com limpeza.

$\S 30$ O locador que prestar qualquer serviço regular de hospedagem deverá obter os cadastros do Ministério do Turismo e os demais cadastros previstos em lei. (BRASIL, 2015, p.1, grifo nosso)

Na prática, essa lei promoveria duas situações: encaixaria os aluguéis via plataformas digitais em “locações para temporada" prevista na Lei Federal № 8.245/1991 através do seu § 2우 proposto. E diferenciaria os locadores ocasionais dos regulares no seu $\S 3$ ㅇ. Nesse sentido, os locadores com serviço regular de hospedagem seriam entendidos como profissionais. O PL № 748/2015 foi arquivado em 27 de Dezembro de 2018.

O segundo projeto de lei, mais recente, é o PL no 2.474/2019 de autoria do Senador Angelo Coronel (PSD-BA). O projeto, ainda em tramitação, também propõe alteração da Lei Federal no 8.245/1991, mas dessa vez em outros termos: inclui a necessidade de concordância do condomínio para que o proprietário possa realizar o aluguel via plataforma digital. Além disso, desobriga a necessidade de cadastro junto ao Ministério do Turismo caso o proprietário "não realize a atividade de locação do imóvel profissionalmente" (BRASIL, 2019, p. 2).

Apesar de alterar a mesma lei, o PL de 2019 difere do anterior porque tem, prioritariamente, um caráter de busca de resolução de conflitos de vizinhança. A justificativa do projeto realça a necessidade de equalizar a vontade dos proprietários em obter renda extra com o direito de sossego e segurança dos vizinhos. Lê-se na justificativa do senador:

A proposição que trazemos considera a vontade dos condôminos como o principal fator a ser considerado nesses casos. Prevalecendo entre os condôminos o sentimento de que essa forma de aluguel não traz prejuízo àquela coletividade de proprietários, poderão autorizar esse tipo de uso das unidades habitacionais. [...]

Com isso, estará protegida a função social da propriedade e do próprio condomínio, e ainda o respeito à original destinação do condomínio e ao bem geral daquela coletividade. (BRASIL, 2019, p. 3)

Ambos os projetos de lei federal propõem a diferenciação entre o proprietário eventual locador e o profissional. Embora façam alterações na Lei do Inquilinato, alegando que o tipo de hospedagem ofertado pelo Airbnb é uma "locação de temporada", os projetos indicam que no caso de exercício "regular" (BRASIL, 2015) ou "profissionalmente" (BRASIL, 2019) o proprietário deve ser enquadrado na Lei Federal no 11.771/2008 (Lei Geral de Turismo) e, portanto cumprir com as obrigações de um prestador de serviços nos termos dessa lei. Falta, no entanto, detalhar como definir o limiar entre os dois modos de exercício e os mecanismos de fiscalização. 
Construindo um paralelo com a tipologia proposta por Nieuwland e Melik (2018), as legislações brasileiras estão construídas baseadas somente em restrições qualitativas e quantitativas, como pode se ver na Tabela 4.

Tabela 4: Restrições das leis municipais brasileiras à atuação do Airbnb.

\begin{tabular}{|c|c|c|}
\hline $\begin{array}{l}\text { Cidade e } \\
\text { legislação }\end{array}$ & $\begin{array}{c}\text { Restrições } \\
\text { quantitativas }\end{array}$ & Restrições qualitativas \\
\hline $\begin{array}{l}\text { Brasil - Projeto } \\
\text { de Lei Federal no } \\
\quad 748 / 2015\end{array}$ & $\begin{array}{l}\text { - Diárias de, no } \\
\text { máximo, } 90 \text { dias } \\
\text { contínuos* }\end{array}$ & $\begin{array}{l}\text { - Cadastro junto ao Ministério do Turismo e os } \\
\text { demais cadastros previstos em lei }\end{array}$ \\
\hline $\begin{array}{l}\text { Brasil - Projeto } \\
\text { de Lei Federal no } \\
\text { 2.474/2019 }\end{array}$ & $\begin{array}{l}\text { - Diárias de, no } \\
\text { máximo, } 90 \text { dias } \\
\text { contínuos* }\end{array}$ & $\begin{array}{l}\text { - Concordância do condomínio } \\
\text { - Cadastro junto ao Ministério do Turismo apenas em } \\
\text { caso de exercício profissional de locação }\end{array}$ \\
\hline $\begin{array}{lr}\text { Caldas } & \text { Novas } \\
\text { (GO) }- & \text { Lei } \\
\text { Municipal } & \text { no } \\
99 / 2017 & \end{array}$ & $\begin{array}{l}\text { - Diárias de, no } \\
\text { máximo, } 90 \text { dias } \\
\text { contínuos }\end{array}$ & $\begin{array}{l}\text { - Emissão de licença, pagamento de ISS, adequação à } \\
\text { regras sanitárias e do condomínio } \\
\text { - Advertência, multa e cancelamento da licença em } \\
\text { caso descumprimento }\end{array}$ \\
\hline $\begin{array}{l}\text { Ubatuba (SP) - } \\
\text { Lei Municipal no } \\
4.050 / 2017 \\
\text { (Revogada) }\end{array}$ & $\begin{array}{l}\text { - Diárias de, no } \\
\text { máximo, } 45 \text { dias } \\
\text { contínuos }\end{array}$ & $\begin{array}{l}\text { - Emissão de licença, pagamento de ISS, adequação à } \\
\text { regras sanitárias e do condomínio, cadastro junto } \\
\text { ao município, Ministério da Fazenda, Ministério do } \\
\text { Turismo } \\
\text { - Multa por descumprimento para agência } \\
\text { mediadora }\end{array}$ \\
\hline $\begin{array}{l}\text { Ubatuba (SP) - } \\
\text { Lei Municipal no } \\
4.140 / 2019\end{array}$ & - & $\begin{array}{l}\text { - Emissão de licença, pagamento de ISS, adequação à } \\
\text { regras sanitárias e do condomínio, cadastro junto } \\
\text { ao município } \\
\text { - Advertência e multa por descumprimento }\end{array}$ \\
\hline
\end{tabular}

A partir desses cinco exemplos apresentados - duas leis municipais vigentes, uma lei municipal revogada e dois projetos de lei de âmbito federal - sendo estas as únicas legislações referentes ao debate da regulação do Airbnb no Brasil, é possível afirmar que tais marcos regulatórios brasileiros (aprovados, revogados e em debate) se aproximariam mais dos modelos "laissez-faire", porque não estabelecem um controle e/ou monitoramento do avanço das unidades no espaço urbano. Não existem restrições locacionais ou de densidade, que são abordagens que limitam a quantidade total de unidades e o confinamento em determinadas regiões. Sendo que no caso de Ubatuba, a segunda lei é ainda mais permissiva, sem nem mesmo estabelecer restrições quantitativas ou previsão de cancelamento da licença em caso de descumprimento. 
Apesar de as duas legislações municipais criarem procedimentos burocráticos, obrigarem o proprietário a se adequar as regras edilícias do condomínio e cumprir com o pagamento de impostos, essas medidas não garantem um monitoramento efetivo da presença do Airbnb nas cidades. Conforme relatado por Slee (2017) e Wachsmuth e Weisler (2018), o Airbnb não está disposto a liberar os dados das unidades disponíveis de bom grado. Sendo assim, não fazendo um monitoramento das unidades, como poderiam os órgãos municipais das duas cidades garantir que os 1638 imóveis em Caldas Novas e 5468 em Ubatuba (AIRDNA, 2019) estão de fato cumprindo com as obrigações impostas? Se a regulamentação dos proprietários dentro da plataforma sequer garante que os imóveis de fato farão o registro e que haja o monitoramento, menos ainda garantirá o controle do aumento de unidades na cidade e a efetiva mitigação das possíveis externalidades negativas no espaço e dinâmica urbana.

\section{CONCLUSÕES}

Conforme exposto por Katz (2015) e Silva, Paiva e Diniz (2017), as empresas que operam na Economia do Compartilhamento exigem regulações inovadoras por se tratarem de empresas com caráter disruptivo e premissas de negócio diferentes das empresas ditas tradicionais. Neste estudo mostramos que, apesar do Airbnb não ser uma exceção a essa regra, os escassos marcos regulatórios brasileiros para esse agente não propõem abordagens que mergulhem dentro da lógica da Economia do Compartilhamento para estruturar leis em diálogo com esse novo modelo de mercado. Pelo contrário, as legislações aplicadas pelos municípios brasileiros, até o presente momento (setembro de 2019), têm se valido de estratégias já existentes no controle desse agente: emissões de licenças, cadastros e limitação de dias.

Dessa forma, o debate da regulação do Airbnb no Brasil tem apontado para três direções: enquadrar o aluguel via plataforma nos moldes da locação de temporada já prevista em lei desde 1991; minimizar os impactos de vizinhança e equalizar os conflitos condominiais com a liberdade de uso da propriedade privada; e diferenciar o uso residencial do uso comercial através de cadastro junto ao Ministério do Turismo e arrecadação de taxas.

Por um lado, o cenário brasileiro difere do debate identificado nas legislações já aplicadas no exterior na medida em que não discute o impacto ao acesso à moradia e gentrificação, não propõe formas de controlar e limitar o avanço das plataformas e não indica mecanismos de fiscalização desses agentes. Apesar de que as operações do Airbnb podem tecnicamente ser enquadradas como locação de temporada, pelos impactos descritos até aqui, nota-se que a dimensão desse fenômeno requer 
outros modos de regulação além dos já existentes. Diferencia-se também do debate em curso na literatura científica ao não vislumbrar o requerimento e uso dos dados das plataformas digitais para implementação da legislação.

Por outro lado, o estado da discussão demonstra entendimento da diferenciação entre o locador ocasional e profissionais da locação. Essa distinção se faz essencial para que se diferencie locadores ocasionais buscando uma renda extra de grandes proprietários e corretores que transformam imóveis de uso residencial em comercial, evadem impostos e contribuem para a descaracterização do tecido social.

Considerando o panorama internacional de regulações do Airbnb, identificam-se três grandes grupos de abordagem: banimento total; permissão com restrições; e laissez-faire (NIEUWLAND; MELIK, 2018). As regulações brasileiras se encaixam no segundo grupo, sendo as restrições qualitativas o maior foco das duas legislações vigentes. Nota-se porém, que as restrições observadas regulamentam a atuação do Airbnb sem, no entanto, atuar no controle e monitoramento do avanço. Dessa forma, esses marcos regulatórios não agem para expandir os benefícios que o Airbnb pode gerar para cidade, tampouco atacam as externalidades negativas que o agente pode causar. Por outro lado, a pesquisa apontou que até o momento, apenas duas cidades possuem legislações referentes ao Airbnb, apesar deste já estar presente em praticamente todos os municípios brasileiros (turísticos ou não), revelando o estágio de laissez-faire (a não regulação), seja por opção ou por dificuldade desta construção regulatória.

O pioneirismo de criação de legislações em duas cidades com forte caráter turístico e uma significativa cadeia de serviços de hospedagem não deixa de chamar atenção. No caso de Ubatuba, soma-se o imbróglio judicial, associado a um lobby do setor hoteleiro, para alimentar a noção de que o surgimento dessas legislações nessas cidades específicas tenha, de fato, relação com a concorrência com esse setor.

O papel desempenhado pelas três legislações (vigente em Caldas Novas e a vigente e a revogada em Ubatuba), se não intencionalmente, fatalmente é o de colocar os proprietários em concorrência mais justa com outros serviços de hospedagem como hotéis e pousadas, ao recolher impostos, colocar obrigações sanitárias e de segurança aos proprietários. Não que isso não seja importante, entretanto quando comparadas às legislações internacionais que buscam uma equalização quanto aos problemas gerados no setor da habitação, os marcos legais privilegiam o embate com o setor de hospedagem e conflitos condominiais, deixando a questão da habitação desassistida. 
Considerando a matriz de agentes, interesses e objetivos proposta por Aguilera, Artioli e Colomb (2019b) e a análise das legislações propostas e em vigência, apontamos que estas regulações refletem os conflitos entre a indústria hoteleira, que busca concorrência mais justa com o Airbnb, associações de moradores, que buscam reduzir incômodos na vizinhança e associações de anfitriões "compartilhadores", que querem utilizar sua propriedade livremente.

Ao expor os possíveis conflitos entre o mercado Airbnb e os mercados de aluguéis, atentamos que essas legislações podem não estar atentas ao território regulado em todos os seus aspectos, principalmente aos conflitos com os mercados de aluguéis e os processos gentrificadores. Importante salientar que nesses dois impactos, o público impactado é difuso, não diretamente identificado como um "agente" na tabela de grupos de interesse na dinâmica de Airbnb. Neste contexto, entendemos que é papel do Estado compreender o Airbnb como um mercado e atuar na sua regulação como forma de garantir concorrência justa com o setor de hospedagem pré-existente, mas primordialmente para mitigar alterações no tecido urbano e social e assegurar que não haja escassez de oferta à habitação permanente, evitar os processos gentrificadores e garantir o cumprimento da função social da cidade e da propriedade. Cabe ao Estado regular os usos e práticas de serviços com objetivo de defender o interesse público e evitar os impactos difusos, mas que incidem concretamente na vida dos moradores da cidade, como são os decorrentes da presença do Airbnb.

\section{REFERÊNCIAS BIBLIOGRÁFICAS}

AGUILERA, T.; ARTIOLI, F.; COLOMB, C. Explaining the diversity of policy responses to platformmediated short-term rentals in European cities: A comparison of Barcelona, Paris and Milan, Environment and Planning A: Economy and Space, v. 1, n. 24, 2019a. p. 1-24.

AGUILERA, T.; ARTIOLI, F.; COLOMB, C. Las villes contre Airbnb? Locations meublées de courte durée, plateformes numériques et gouvernance urbaine. In: COURMONT, A.; GALÈS, P. L. Gouverner la ville numérique. Paris: Presses Universitaires de France, 2019b. p. 27-45.

AIRBNB in Brazil: Community and Economic Activity, 2016. Disponível em < https://2sqy5r1jf93u30kwzc1smfqt-wpengine.netdnassl.com/wpcontent/uploads/2017/06/EconomicReport_Brazil.pdf > Acesso em 20 jul, 2018.

AIRBNB. Disponível em: http://airbnb.com. Acesso em 23 jul. 2019.

AIRDNA.CO. Disponível em: http://airdna.co. Acesso em 28 set. 2019.

AJUNTAMENT de Barcelona (2017). About the PEAUT (Special tourism accommodation plan). Disponível em: https://ajuntament.barcelona.cat/pla-allotjaments-turistics/en/. Acesso em: 17 jun. 2020. 
Barcelona multará Airbnb em 600.000 euros por anunciar apartamentos sem licenças. Gazeta do Povo, Curitiba, nov. 2016. Disponível em: https://www.gazetadopovo.com.br/vida-ecidadania/futuro-das-cidades/barcelona-multara-airbnb-em-600000-euros-por-anunciarapartamentos-sem-licencas-aoa0vbm4nljfoiodaeiohc05p/. Acesso em 10 abr. 2019.

BATEMAN, J. Athens property boom: Greeks left out as prices rise. BBC, Atenas, feb. 2019. Disponível em: https://www.bbc.com/news/world-europe-47237923. Acesso em 20 mar. 2019.

BELARMINO, A.; KOH, Y. A critical review of reseach regarding peer-to-peer accommodations. International Journal of Hospitality Management, v. 84, p. 1-15, 2020.

Berlim reforça cerco contra aluguel por temporada em sites como Airbnb. Folha de São Paulo, São Paulo, abr. 2016. Disponível em: https://www1.folha.uol.com.br/turismo/2016/04/1766335-berlimreforca-cerco-contra-aluguel-por-temporada-em-sites-como-airbnb.shtml. Acesso em 10 abr. 2019.

BERSHIDSKY, L. Airbnb começa a ceder a exigências legais de cidades onde atua. Gazeta do Povo, Curitiba, dez. 2016. Disponível em: https://www.gazetadopovo.com.br/vida-e-cidadania/airbnbcomeca-a-ceder-a-exigencias-legais-de-cidades-onde-atua-dpphzmwsfan2qzfpxw289q7xs/. Acesso em 10 abr. 2019.

BOHÓRQUEZ, L. Palma é a primeira cidade espanhola a proibir aluguel turístico, como Airbnb. El País, Palma de Mallorca, abr. 2018. Disponível em: https://brasil.elpais.com/brasil/2018/04/23/internacional/1524493873_547313.html. Acesso em 13 abr. 2019.

BRASIL. Lei Federal no 8.245, de 18 de outubro de 1991. Dispõe sobre as locações dos imóveis urbanos e os procedimentos a elas pertinentes. Disponível em http://www.planalto.gov.br/ccivil_03/leis/L8245.htm. Acesso em 15 ago. 2019.

BRASIL. Lei Federal no 11.771, de 17 de setembro de 2018. Dispõe sobre a Política Nacional de Turismo, define as atribuições do Governo Federal no planejamento, desenvolvimento e estímulo ao setor turístico; revoga a Lei no 6.505, de 13 de dezembro de 1977, o Decreto-Lei no 2.294, de 21 de novembro de 1986, e dispositivos da Lei no 8.181, de 28 de março de 1991; e dá outras providências. Disponível em http://www.planalto.gov.br/ccivil_03/_Ato2007-2010/2008/Lei/L11771.htm. Acesso em 15 ago. 2019.

BRASIL. Projeto de Lei Federal no 748 de 24 de novembro de 2015. Altera a Lei no 8.245, de 18 de outubro de 1991 para atualizar o regime da locação para temporada, disciplinando a atividade de compartilhamento de imóveis residenciais por meio de sítios eletrônicos ou aplicativos. Disponível em: https://legis.senado.leg.br/sdleg-

getter/documento?dm=4177147\&ts=1559267810700\&disposition=inline. Acesso em 30 ago. 2019.

BRASIL. Projeto de Lei Federal no 2.474 de 23 de abril de 2019. Altera a Lei no-8.245, 18 de outubro de 1991, para disciplinar a locação de imóveis residenciais por temporada por meio de plataformas de intermediação ou no âmbito da economia compartilhada. Disponível em:

https://www25.senado.leg.br/web/atividade/materias/-/materia/136443 Acesso em 21 jul. 2020.

BROSSAT, lan. Airbnb, la ciudad uberizada. Pamplona: Katakrak Liburuak, 2019. 148p. 
BUONO, M. Ubatuba (SP) recua em regulação sobre alugueis de temporada. PanRotas, São Paulo, 19 dez. 2018. Disponível em: https://www.panrotas.com.br/hotelaria/mercado/2018/12/ubatuba-sprecua-em-regulacao-sobre-alugueis-de-temporada_161150.html. Acesso em 26 ago. 2019.

CALDAS NOVAS. Lei Complementar Municipal no 99, de 18 dezembro de 2017. Que regulamenta a exploração de imóveis residenciais como meio de hospedagem remunerada no município de Caldas Novas/GO, e dá outras providências. Caldas Novas: Câmara Municipal, [2017]. Disponível em: http://leis.camaradecaldas.go.gov.br/wp-content/uploads/2018/02/Lei-Complementar-099-2017Regulamenta-a-exploração-de-imóveis-residenciais-como-meio-de-hospedagem-remunerada-nomunic\%C3\%ADpio-de-Caldas-NovasGO.pdf. Acesso em 2 abr. 2019.

CAPELLI, P. Prefeitura envia à Câmara projeto de lei para cobrar imposto de aplicativos de hospedagem. O Dia, Rio de Janeiro, set. 2018. Disponível em:

https://odia.ig.com.br/colunas/informe-do-dia/2018/09/5578246-crivella-enviara-projeto-de-leipara-cobrar-iss-de-portais-virtuais.html. Acesso em 17 abr. 2019.

COLES, P.; EGESDAL, M.; ELLEN, I. G.; LI, X.; SUNDARARAJAN, A. Airbnb Usage Across New York City Neighborhoods: Geographic Patterns and Regulatory Implications, Cambrigdge Handbook of the Law of the Sharing Economy. New York, out. 2017.

DINATALE, S.; LEWIS, R.; PARKER, R. Short-term rentals in small cities in Oregon: Impacts and regulations. Land Use Policy, v. 79, p. 407-423, 2018.

ECKHARDT, G. M.; BARDHI, F. The Sharing isn't about sharing at all. Harvard Business Review, Boston, jan. 2015. Disponível em: https://hbr.org/2015/01/the-sharing-economy-isnt-about-sharingat-all. Acesso em 10 abr. 2019.

ESTIMATIVAS da população residente no brasil e unidades da federação. Estimativas da População. Rio de Janeiro: IBGE, 2019. Disponível em:

https://www.ibge.gov.br/estatisticas/sociais/populacao/9103-estimativas-depopulacao.html?=\&t=resultados. Acesso em 20 ago. 2019.

FERRER, I. Cidades europeias saturadas de turistas se unem contra o Airbnb. El País, Amsterdã, jan. 2018. Disponível em: https://brasil.elpais.com/brasil/2018/01/28/economia/1517154558_ 107147.html. Acesso em 19 jul. 2018.

FERRERI, M.; SANYAL, R. Platform economies and urban planning: Airbnb and regulated deregulation in London. Urban Studies, London, v. 55, n. 15, p. 3353-3368, 2018.

FRENKEN, K.; SCHOR, J. Putting the sharing economy into perspective. Environmental Innovation and Societal Transitions. v. 23, p. 3-10, 2017.

FURUKAWA, N.; ONUKI, M. The design and effects of short-term rentals regulation. Current Issues in Tourism, v. 22, 2019. p. 1-16.

GALLAGHER, L. La historia de Airbnb: como tres chicos comunes transtornaron una industria, ganaron miles de milones y crearon gran controversia. Bogotá: Conecta, 2019. 271p.

GURRAN, N.; PHIBBS, P. When Tourists Move In: How Should Urban Planners Respond to Airbnb?. Journal of the American Planning Association, Chicago, IL, v. 83, n. 1, p. 80-92, jan. 2017. 
GURRAN, N. Global Home-Sharing, Local Communities and the Airbnb Debate: A Planning Research Agenda. Planning Theory \& Practice, v. 9, n. 2. p. 298-303, 2018.

GUTIÉRREZ, J.; ROMANILLOS, G.; GARCÍA-PALOMARES, J. C.; SALAS-OLMEDO, M. H. The eruption of Airbnb in tourist cities: Comparing spatial patterns of hotels and peer-to-peer accommodation in Barcelona. Management Journal, Madrid, v.62, p.278- 291, 2017.

GUTTENTAG, D. What Airbnb really does to a neighbourhood. BBC, Charleston, aug. 2018. Disponível em: https://www.bbc.com/news/business-45083954. Acesso em 16 abr. 2019.

HOLM, Eric Joseph van. Evaluating the impact of short-term rental regulations on Airbnb in New Orleans. Cities, v. 104, n. 9, 2020. p. 1-9.

INTERIAN, J. Up in the Air: Harmonizing the Sharing Economy Through Airbnb Regulations. Boston College International and Comparative Law Review, Boston, v. 39, n. 1, p. 128-161, 2016.

KAPLAN, R. A.; NADLER, M. L. Airbnb: A Case Study in Occupancy Regulation and Taxation. University of Chicago Law Review Online, Chicago, IL, v. 82, n. 1, p. 103-115, 2017.

KATZ, V. Regulating the Sharing Economy. Berkeley Technology Law Journal, Berkeley, v.30 , n.4, p. 1067-1126, nov. 2015.

KOOPMAN, C.; MITCHELL, M.; THIERER, A. The Sharing Economy and Consumer Protection Regulation: The Case for Policy Change. The Journal of Business, Entrepreneurship \& the Law, v. 8, n. 2, p. 529-547, maio 2015. Disponível em: http://digitalcommons.pepperdine.edu/jbel/ vol8/iss2/4. Acesso em 19 jul. 2018.

LEE, D. How Airbnb Short-Term Rentals Exacerbate Los Angeles's Affordable Housing Crisis: Analysis and Policy Recommendations. Harvard Law and Policy Review. Cambridge, v. 10, feb. 2016.

LISBOA. Alteração ao Regulamento Geral de Taxas, Preços e Outras Receitas do Município de Lisboa. Lisboa, 26 dez. 2018. Disponível em: http://www.cm-lisboa.pt/servicos/pedidos/pagamentostaxas-e-tarifas/taxa-municipal-turistica-de-dormida/legislacao. Acesso em 10 abr. 2019.

MCKEE, D. The platform economy: natural, neutral, consensual and efficient? Transnational Legal Theory, v. 8, n. 4, p. 455-495, dez. 2017.

MENEZES, F. Z. Saída para regulação de Airbnb no Brasil pode ser a "desregulamentação geral". Gazeta do Povo, Curitiba, dez. 2016. Disponível em: https://www.gazetadopovo.com.br/vida-ecidadania/futuro-das-cidades/saida-para-regulacao-de-airbnb-no-brasil-pode-ser-adesregulamentacao-geral-. Acesso em 10 abr. 2019.

MERANTE, M.; HORN, K. M. Is home sharing driving up rents? Evidence from Airbnb in Boston. Journal of Housing Economics, Boston, v.38, p.14-24, 2017.

Metrópoles turísticas limitam o avanço do Airbnb. Folha de São Paulo, São Paulo, jul. 2018. Disponível em: https://www1.folha.uol.com.br/mercado/2018/07/metropoles-turisticas-limitam-oavanco-do-airbnb.shtml. Acesso em 14 abr. 2019. 
NASCIMENTO, J. L. Como uma inovação tecnológica afeta mercados preexistentes? Evidência do impacto da entrada do Airbnb nos mercados hoteleiro e imobiliário de Nova York. 2018. $41 \mathrm{f}$. Dissertação (Mestrado em Economia) - Universidade Católica de Brasília, Brasília, DF, 2018.

NIEUWLAND, S.; MELIK, R. V. Regulating Airbnb: how cities deal with perceived negative externalities of short-term rentals. Current Issues in Tourism, v.21, p. 1-15, ago. 2018.

NÚMERO de estabelecimentos de hospedagem, número de unidades habitacionais e número de leitos, por tipos de estabelecimentos - Resultados Municipais. Pesquisa de serviços de hospedagem 2016. Rio de Janeiro: IBGE, 2016. Disponível em: Https://sidra.ibge.gov.br/pesquisa/psh/tabelas. Acesso em 30 ago. 2019.

OLIVEIRA, C. A regulamentação do Airbnb no Brasil e em outro países. Consultor Jurídico, Rio de Janeiro, mar. 2019. Disponível em: https://www.conjur.com.br/2019-mar-04/camila-oliveiraregulamentacao-airbnb-brasil-mundo. Acesso em 18 abr. 2019.

PAVÃO, J. V.; VITA, J. B. Desafios regulatórios do Caso Airbnb: a intervenção do Estado no modelo econômico colaborativo. Justiça do Direito, Passo Fundo, v. 32, n.1, p 203-230, jan./abr. 2018.

PEOPLE WHO SHARE. Disponível em: https://www.thepeoplewhoshare.com/. Acesso em 22 ago. 2019.

QUATTRONE, G.; NICOLAZZO, S.; NOCERA, A.; QUERCIA, D.; CAPRA, L. Is the Sharing Economy about Sharing at All? A linguisct analysis of Airbnb Reviews. In: INTERNATIONAL AAAI CONFERENCE ON WEB AND SOCIAL MEDIA, 20, 2018, Palo Alto. Proceedings. Palo Alto: AAAI Press, 2018. p. 668-671

QUATTRONE, G.; PROSERPIO, D.; QUERCIA, D.; CAPRA, L.; MUSOLESI, M. Who benefits from the "Sharing" Economy of Airbnb?. In: 25TH INTERNATIONAL CONFERENCE ON WORLD WIDE WEB PAGES, 25, 2016, Montreal. Proceedings. Montréal: WWC16, 2016. p. 1385-1394.

RIBAS, R. Começa a regulamentação de aluguéis de curta duração no Brasil. O Globo, Rio de Janeiro, jan. 2018. Disponível em: https://oglobo.globo.com/economia/imoveis/comeca-regulamentacao-dealuguéis-de-curta-duracao-no-brasil-22312806. Acesso em 12 abr. 2019.

SALOMÃO, K. De desempregado a bilionário: a vida do CEO do Airbnb. EXAME, São Paulo, jun. 2016. Disponível em: https://exame.abril.com.br/negocios/de-desempregado-a-bilionario-a-vida-do-ceodo-airbnb/. Acesso em 20 jul. 2018.

SCHOR, J. Debatendo a Economia do Compatilhamento. In: ZANATTA, R. A. F; PAULA, P. C. B.; KIRA; B. (orgs). Economias do Compartilhamento e o Direito. 1 ed. Curitiba, 2017. p. 21-40.

SEARA, B.; MACEDO, A. Câmara do Rio analisa se projeto para cobrar ISS de Airbnb segue adiante. Extra, Rio de Janeiro, abr. 2019. Disponível em: https://extra.globo.com/noticias/extraextra/camara-do-rio-analisa-se-projeto-para-cobrar-iss-de-airbnb-segue-adiante-23564912.html. Acesso em 12 abr. 2019.

SHEPARD, S.; UDELL, A. Do Airbnb properties affect house prices? Department of Economics Working Papers from Department of Economics, Williams College, Williamstown, n. 3, out. 2016. 
SILVA, R. A.; PAIVA, M. S.; DINIZ, G. S. Desafios Jurídico-Regulatórios e Economia Compartilhada: Elementos para uma Reflexão Crítica. Scientia luris, Londrina, PR, v. 21, n. 2, p. 98-125, jul. 2017.

SLEE, T. Uberização: A nova onda do trabalho precarizado.1a edição. São Paulo: Editora Elefante, 2017. 320p.

SUNDARARAJAN, A. Economia compartilhada: o fim do emprego e a ascensão do capitalismo de multidão. São Paulo: Editora SENAC, 2018. 303p.

TAVOLARI, B. Airbnb e os impasses regulatórios para o compartilhamento de moradia: Notas para uma agenda de pesquisa em Direito. In: ZANATTA, R. A. F.; PAULA, P. C. B.; KIRA, B. (orgs). Economias do Compartilhamento e o Direito. Curitiba: Juruá, 2017. 388p.

THE CITY OF PORTLAND OREGON. Title 33 Planning and Zoning. Portland, 31 mar. 2017. Disponível em: https://www.portlandoregon.gov/citycode/28197. Acesso em: 23 jul. 2018.

THOMPSON, D. Airbnb and the Unintended Consequences of 'Disruption'. The Atlantic, Boston, fev. 2018. Disponível em: https://www.theatlantic.com/business/archive/2018/02/airbnb-hotelsdisruption/553556/. Acesso em 10 abr. 2019.

THOMPSON, D. Airbnb CEO Brian Chesky on Building a Company and Starting a 'Sharing' Revolution. The Atlantic, Boston, ago. 2013. Disponível em: https://www.theatlantic.com/business/ archive/2013/08/airbnb-ceo-brian-chesky-on-building-a-company-and-starting-a-sharingrevolution/278635/. Acesso em 24 jul. 2018.

UBATUBA. Lei no 4.050, de 20 de dezembro de 2017. Estabelece a regulamentação das hospedagens Cama\&Café e Residenciais por Temporada no Município de Ubatuba. Ubatuba: Câmara Municipal, [2017]. Disponível em https://camaraubatuba.sp.gov.br/documentos/leis/2017/I_4050_2017.pdf Acesso em 20 ago. 2019.

UBATUBA. Lei no 4.140, de 20 janeiro de 2019. Disciplina a instalação e funcionamento do meio de hospedagem remunerado em residência com prestação de serviços no município de Ubatuba/SP, e dá outras providências. Ubatuba: Câmara Municipal, [2019]. Disponível em:

https://camaraubatuba.sp.gov.br/documentos/leis/2019/I_4140_2019.pdf. Acesso em 20 ago. 2019.

WACHMUSTH, D.; WEISLER, A. Airbnb and the rent gap: Gentrification through the sharing economy. Environment and Planning A: Economy and Space, London, v. 50, n. 6, p. 1147-1170, 2018.

WEGMANN, J.; JIAO, J. Taming Airbnb: Toward guiding principles for local regulation of urban vacation rentals based on empirical results from five US cities. Land Use Policy, v. 69, p. 494-501, 2017.

ZERVAS, G.; PROSERPIO, D.; BYERS, J. W. The rise of sharing economy: Estimating the impact of Airbnb on the Hotel Industry. Journal of Marketing Research, Boston, v. 54, n. 5, p. 687- 705, 2016. 